\title{
Scintillation and Dosimetric Properties of Monocrystalline and Polycrystalline $\mathrm{Li}_{2} \mathrm{~B}_{4} \mathrm{O}_{7}$
}

\author{
Noriaki Kawaguchi, ${ }^{1 *}$ Go Okada, ${ }^{2}$ Yoshisuke Futami, ${ }^{3}$ \\ Daisuke Nakauchi, ${ }^{1}$ Takumi Kato, ${ }^{1}$ and Takayuki Yanagida ${ }^{1}$ \\ ${ }^{1}$ Nara Institute of Science and Technology, 8916-5 Takayama-cho, Ikoma, Nara 630-0192, Japan \\ ${ }^{2}$ Department of Applied Chemistry, Kanazawa Institute of Technology, \\ 7-1 Ohgigaoka, Nonoichi, Ishikawa 921-8501, Japan \\ ${ }^{3}$ Department of Biological and Chemical Systems Engineering, National Institute of Technology, \\ Kumamoto College, 2627 Hirayamashin-Machi, Yatsushiro, Kumamoto 866-8501, Japan
}

(Received December 22, 2019; accepted March 16, 2020)

Keywords: scintillator, dosimeter, luminesce, trapping center

We have performed a comparative study on the scintillation and dosimetric properties of monocrystalline and polycrystalline $\mathrm{Li}_{2} \mathrm{~B}_{4} \mathrm{O}_{7}$ samples. The scintillation light yield of the monocrystalline $\mathrm{Li}_{2} \mathrm{~B}_{4} \mathrm{O}_{7}$ sample was higher than that of the polycrystalline $\mathrm{Li}_{2} \mathrm{~B}_{4} \mathrm{O}_{7}$ sample. In contrast, the thermoluminescence (TL) intensity of the polycrystalline $\mathrm{Li}_{2} \mathrm{~B}_{4} \mathrm{O}_{7}$ sample was higher than that of the monocrystalline $\mathrm{Li}_{2} \mathrm{~B}_{4} \mathrm{O}_{7}$ sample. These results can be explained by the difference in trap concentration between the monocrystalline and polycrystalline $\mathrm{Li}_{2} \mathrm{~B}_{4} \mathrm{O}_{7}$ samples. It has been assumed that the monocrystalline $\mathrm{Li}_{2} \mathrm{~B}_{4} \mathrm{O}_{7}$ sample shows a higher scintillation light yield owing to its lower trap concentration, and the polycrystalline $\mathrm{Li}_{2} \mathrm{~B}_{4} \mathrm{O}_{7}$ sample shows a higher TL intensity owing to its higher trap concentration.

\section{Introduction}

Industrial, medical, and scientific applications of ionizing radiation require both radiation detection and dosimetry techniques. The radiation detection technique allows us to measure energies and amounts of ionizing radiation immediately, and the radiation dosimetry technique allows us to measure radiation doses for a certain period of time.

In the radiation detection technique, scintillation counters ${ }^{(1)}$ are widely used because their detection efficiency is higher than those of gas proportional counters and semiconductor-type detectors. This higher detection efficiency is achieved by scintillators ${ }^{(2,3)}$ that are one of the elementary components of scintillation counters. Typical scintillators are solid-state phosphors with higher densities than gases and larger thicknesses than semiconductor film devices. Scintillators can more efficiently convert ionizing radiation to visible light than many other phosphors and are combined with photodetectors; thus, scintillation counters can indirectly detect ionizing radiation. Since there are various types of scintillator, scintillation counters can detect different types of ionizing radiation, such as X-rays,${ }^{(4)} \gamma$-rays,${ }^{(5)}$ charged particles, ${ }^{(6)}$ and

*Corresponding author: e-mail: n-kawaguchi@ms.naist.jp

https://doi.org/10.18494/SAM.2020.2752 
neutrons. ${ }^{(7-11)}$ These scintillators are used for medical imaging, ${ }^{(4)}$ nondestructive inspection, ${ }^{(12)}$ and well logging. ${ }^{(13,14)}$ Although many types of scintillator have been reported, it is still attractive to develop novel scintillators with higher light yields ${ }^{(15-26)}$ and shorter decay times. ${ }^{(27,28)}$

In the radiation dosimetry technique, personal dosimeters are made of dosimetric materials that are mainly solid-state storage phosphors. ${ }^{(29)}$ Storage phosphors can store excited electrons and holes in their trapping centers after irradiation. Captured electrons and holes can be released by thermal or optical stimulation and recombine at luminescent centers. Storage phosphors that emit light by thermal and optical stimulations are called thermoluminescence $(\mathrm{TL})^{(30)}$ and optically stimulated luminescence $(\mathrm{OSL})^{(31,32)}$ dosimetric materials, respectively. Radio-photoluminescence (RPL) ${ }^{(33-35)}$ dosimetric materials are another choice for the radiation dosimetry technique. In RPL materials, new luminescent centers are generated by irradiation typically owing to valence changes of dopant ions. As well as research for scintillators, it is still attractive to develop novel TL, ${ }^{(36-39)}$ OSL, ${ }^{(40-42)}$ and $\mathrm{RPL}^{(43,44)}$ materials.

In addition to the novel material research for scintillators and dosimetric materials, we are interested in comparisons between scintillation and dosimetric properties. In general, scintillators and dosimetric materials are individually studied; however, some materials can show both scintillation and storage luminescence (TL and OSL), ${ }^{(45-48)}$ and their correlation is also attractive. We have actually reported an inverse correlation between OSL intensities and scintillation light yields of Ce-doped $\mathrm{CaF}_{2}$ single crystals with similar compositions. ${ }^{(49)}$ This correlation is assumed to be due to a difference in trap concentration; that is, an increase in the trapping center density of phosphor materials tends to reduce their scintillation light yield and increase their storage luminescence intensity. In this manner, the comparative study between scintillation and dosimetric properties can be useful for a better understanding of the luminescence phenomena of phosphors after exposure to ionizing radiation. We are expecting that this study will contribute to the novel material research.

To make progress in this comparative study, we have focused on another material, $\mathrm{Li}_{2} \mathrm{~B}_{4} \mathrm{O}_{7}$, which has been reported as both a neutron scintillator ${ }^{(50)}$ and a dosimeter material. ${ }^{(51-53)}$ There are few host crystals that can be used for both applications. For example, $\mathrm{CaF}_{2}$ is applied as the host crystal of both materials. It is known that Eu-doped $\mathrm{CaF}_{2}$ is used for the scintillator and $\mathrm{Mn}$-doped $\mathrm{CaF}_{2}$ is used for the dosimetric material. In the case of $\mathrm{Li}_{2} \mathrm{~B}_{4} \mathrm{O}_{7}$, both $\mathrm{Cu}$-doped $\mathrm{Li}_{2} \mathrm{~B}_{4} \mathrm{O}_{7}{ }^{(50,52)}$ and nondoped $\mathrm{Li}_{2} \mathrm{~B}_{4} \mathrm{O}_{7}{ }^{(50,51)}$ were reported as the scintillator and dosimetric material. Only as the dosimetric material, Mn-doped $\mathrm{Li}_{2} \mathrm{~B}_{4} \mathrm{O}_{7}{ }^{(53)}$ was studied. Since it is easier to obtain polycrystalline and monocrystalline samples using nondoped $\mathrm{Li}_{2} \mathrm{~B}_{4} \mathrm{O}_{7}$, we have performed a comparative study on the scintillation and dosimetric properties of nondoped $\mathrm{Li}_{2} \mathrm{~B}_{4} \mathrm{O}_{7}$.

\section{Materials and Methods}

We prepared a polycrystalline $\mathrm{Li}_{2} \mathrm{~B}_{4} \mathrm{O}_{7}$ sample by atmospheric sintering in air. As raw materials, high-purity $\mathrm{Li}_{2} \mathrm{CO}_{3}$ and $\mathrm{B}_{2} \mathrm{O}_{3}$ powders were used. The raw powders were mixed in the mole ratio of $\mathrm{Li}_{2} \mathrm{~B}_{4} \mathrm{O}_{7}\left(\mathrm{Li}_{2} \mathrm{CO}_{3}: \mathrm{B}_{2} \mathrm{O}_{3}=1: 2\right)$ and poured into an aluminum crucible. The mixed powders were calcined at $800{ }^{\circ} \mathrm{C}$ for $3 \mathrm{~h}$ in order to remove $\mathrm{CO}_{2}$ and react into $\mathrm{Li}_{2} \mathrm{~B}_{4} \mathrm{O}_{7}$. 
The obtained powder was pressed into a pellet; then, it was sintered at $800{ }^{\circ} \mathrm{C}$ for $3 \mathrm{~h}$. As a monocrystalline $\mathrm{Li}_{2} \mathrm{~B}_{4} \mathrm{O}_{7}$ sample, we used a commercial $\mathrm{Li}_{2} \mathrm{~B}_{4} \mathrm{O}_{7}$ single crystal (OXIDE, Hokuto, Japan) that was cut and polished from a $\mathrm{Li}_{2} \mathrm{~B}_{4} \mathrm{O}_{7}$ single crystal ingot grown by the vertical Bridgman method.

To investigate the optical property of the monocrystalline $\mathrm{Li}_{2} \mathrm{~B}_{4} \mathrm{O}_{7}$ sample, the in-line transmittance spectrum was measured using a spectrophotometer (V-670; JASCO, Hachioji, Japan) across a spectral range from 190 to $2700 \mathrm{~nm}$ in $1 \mathrm{~nm}$ steps. To compare porosities of the samples, their densities were measured by Archimedes' principle using water as the immersion fluid. Furthermore, X-ray diffraction (XRD) patterns were measured using a diffractometer equipped with a $\mathrm{Cu}-\mathrm{K} \alpha \mathrm{X}$-ray source (MiniFlex600; Rigaku, Akishima, Japan). Their crystal phases were identified using the Crystallography Open Database (COD).

$\mathrm{X}$-ray-induced scintillation spectra of the samples were measured using our customized setup including an X-ray generator, an optical fiber, and a spectrometer, the details of which are found elsewhere. ${ }^{(54)}$ The samples were irradiated with X-rays from an X-ray generator (XRB80P\&N200X4550; Spellman High Voltage Electronics, Hauppauge, New York, United States), and their luminescence was guided to the monochromator (Shamrock 163; Andor Technology, Belfast, Northern Ireland) on a CCD-based spectrometer (DU920-BU2NC; Andor Technology). In this experiment, the applied tube voltage and current were set to $40 \mathrm{kV}$ and $1.2 \mathrm{~mA}$, respectively. To evaluate their scintillation light yields, pulse height spectra were measured using a ${ }^{252} \mathrm{Cf}$ sealed source with a polyethylene modulator as a thermal neutron source and a photomultiplier tube (PMT; R7600U-200; Hamamatsu Photonics, Hamamatsu, Japan) as a photodetector. The detailed setup including analog modules for signal analysis is shown in our previous report. ${ }^{(14)}$

To investigate the dosimetric properties of the samples, TL glow curves were measured using a TL reader (TL-2000; Nanogray, Minoh, Japan). The samples were heated at a rate of $1{ }^{\circ} \mathrm{C} / \mathrm{s}$ by elevating the temperature from 50 to $250{ }^{\circ} \mathrm{C}$. Before the measurements, the samples were irradiated with X-rays at certain doses using an X-ray generator (XRB80N100/CB; Spellman High Voltage Electronics). The absorbed doses (air kerma) were determined using an ionization chamber (Model 30013; PTW, Freiburg, Germany). The measurements were repeated with several different irradiation doses from $1 \mathrm{mGy}$ to $10 \mathrm{~Gy}$ to obtain the dose-response curves of the samples, which show a correlation between the TL emission intensities and the irradiation doses.

\section{Results and Discussion}

Figure 1 shows the monocrystalline and polycrystalline $\mathrm{Li}_{2} \mathrm{~B}_{4} \mathrm{O}_{7}$ samples. Both samples have no visible cracks and they seem colorless. The monocrystalline $\mathrm{Li}_{2} \mathrm{~B}_{4} \mathrm{O}_{7}$ sample looks highly transparent. Figure 2 shows the in-line transmittance spectrum of the monocrystalline $\mathrm{Li}_{2} \mathrm{~B}_{4} \mathrm{O}_{7}$ sample. The in-line transmittances of the monocrystalline $\mathrm{Li}_{2} \mathrm{~B}_{4} \mathrm{O}_{7}$ sample in the wavelength range from 400 to $2700 \mathrm{~nm}$ are from approximately 80 to $90 \%$. Its spectral feature is consistent with that of the $\mathrm{Li}_{2} \mathrm{~B}_{4} \mathrm{O}_{7}$ single crystal for nonlinear optical applications in the previous report. ${ }^{(55)}$ Our monocrystalline $\mathrm{Li}_{2} \mathrm{~B}_{4} \mathrm{O}_{7}$ sample for this study also seems to have an 


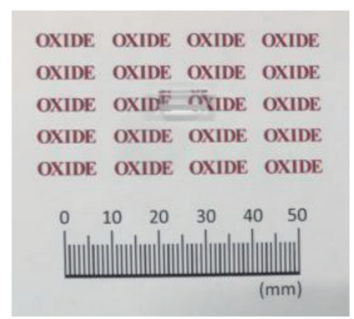

(a)

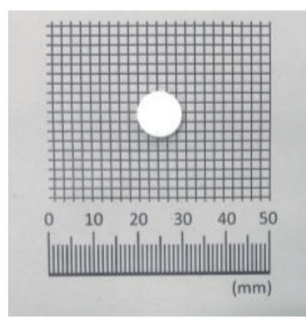

(b)

Fig. 1. (Color online) (a) Monocrystalline and (b) polycrystalline $\mathrm{Li}_{2} \mathrm{~B}_{4} \mathrm{O}_{7}$ samples.

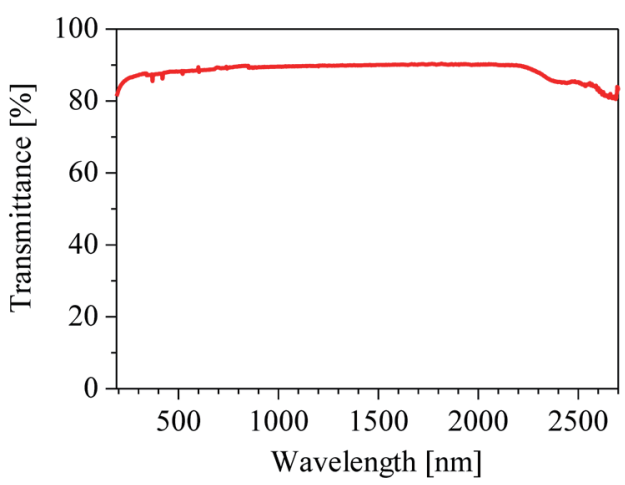

Fig. 2. (Color online) In-line transmittance spectrum of monocrystalline $\mathrm{Li}_{2} \mathrm{~B}_{4} \mathrm{O}_{7}$ sample.

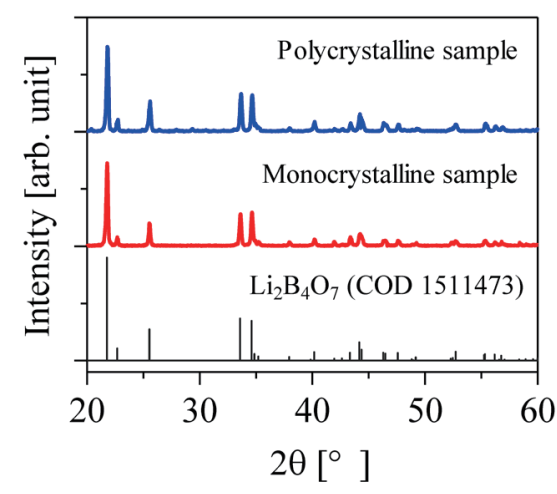

Fig. 3. (Color online) X-ray diffraction patterns of monocrystalline and polycrystalline $\mathrm{Li}_{2} \mathrm{~B}_{4} \mathrm{O}_{7}$ samples.

excellent optical property. The measured densities of the monocrystalline and polycrystalline $\mathrm{Li}_{2} \mathrm{~B}_{4} \mathrm{O}_{7}$ samples are 2.42 and $2.16 \mathrm{~g} / \mathrm{cm}^{3}$, respectively. The polycrystalline $\mathrm{Li}_{2} \mathrm{~B}_{4} \mathrm{O}_{7}$ sample is more porous than the monocrystalline $\mathrm{Li}_{2} \mathrm{~B}_{4} \mathrm{O}_{7}$ sample. Figure 3 shows XRD patterns of monocrystalline and polycrystalline $\mathrm{Li}_{2} \mathrm{~B}_{4} \mathrm{O}_{7}$ samples. The small parts of the samples were used for the measurements. Both samples show XRD peaks that are ascribed to those of the $\mathrm{Li}_{2} \mathrm{~B}_{4} \mathrm{O}_{7}$ phase found in the database (COD 1511473).

Figure 4 shows X-ray-induced scintillation spectra of the monocrystalline and polycrystalline $\mathrm{Li}_{2} \mathrm{~B}_{4} \mathrm{O}_{7}$ samples. Both samples show the broad emission band peaking at the wavelength of $340 \mathrm{~nm}$. These spectral features are similar to those in the previous report. ${ }^{(50)}$ It is considered that these are related to the defect-related luminescence of nondoped $\mathrm{Li}_{2} \mathrm{~B}_{4} \mathrm{O}_{7}$. Figure 5 shows a pulse height spectrum related to the monocrystalline $\mathrm{Li}_{2} \mathrm{~B}_{4} \mathrm{O}_{7}$ sample under neutron irradiation using the ${ }^{252} \mathrm{C}$ f sealed source. In this measurement, the polycrystalline $\mathrm{Li}_{2} \mathrm{~B}_{4} \mathrm{O}_{7}$ sample showed no significant signals probably owing to its significantly lower light yield. Therefore, we show only the pulse height spectrum of the monocrystalline $\mathrm{Li}_{2} \mathrm{~B}_{4} \mathrm{O}_{7}$ sample. From the result, we confirmed two detection peaks that are ascribed to nuclear reactions of ${ }^{6} \mathrm{Li}$ and ${ }^{10} \mathrm{~B}$ with neutrons. These nuclear reactions are shown below. ${ }^{(7)}$

$$
{ }^{6} \mathrm{Li}+\mathrm{n} \rightarrow{ }^{3} \mathrm{H}(2.73 \mathrm{MeV})+{ }^{4} \mathrm{He}(2.05 \mathrm{MeV})
$$




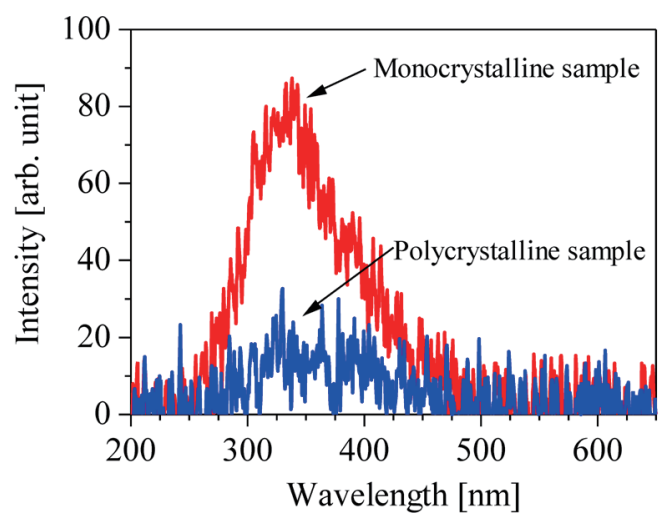

Fig. 4. (Color online) X-ray-induced scintillation spectra of monocrystalline and polycrystalline $\mathrm{Li}_{2} \mathrm{~B}_{4} \mathrm{O}_{7}$ samples.

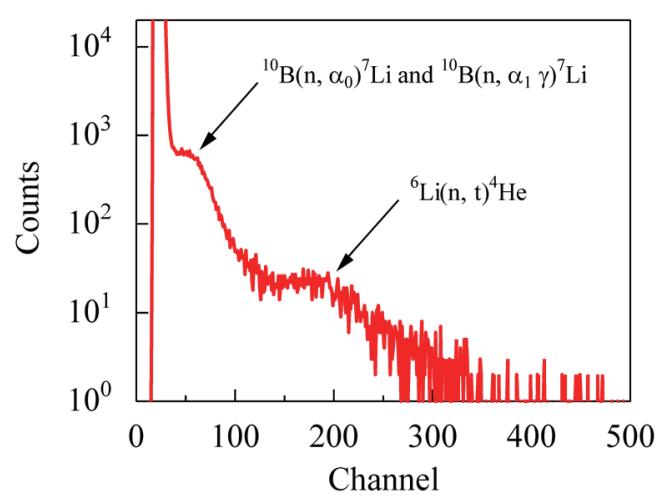

Fig. 5. (Color online) Pulse height spectrum of monocrystalline $\mathrm{Li}_{2} \mathrm{~B}_{4} \mathrm{O}_{7}$ under neutron irradiation using the ${ }^{252} \mathrm{Cf}$ sealed source.

$$
\begin{gathered}
{ }^{10} \mathrm{~B}+\mathrm{n} \rightarrow{ }^{7} \mathrm{Li}(0.84 \mathrm{MeV})+{ }^{4} \mathrm{He}(1.47 \mathrm{MeV})+\gamma \text {-ray }(0.48 \mathrm{MeV})[93 \%] \\
\rightarrow{ }^{7} \operatorname{Li}(1.01 \mathrm{MeV})+{ }^{4} \mathrm{He}(1.78 \mathrm{MeV})[7 \%]
\end{gathered}
$$

The peak channels formed by ${ }^{10} \mathrm{~B}$ and ${ }^{6} \mathrm{Li}$ are 60 and 200, respectively. In the same measurement, a standard neutron scintillator GS20 (Ce-doped lithium silicate glass) shows a peak at 7400 channels. If the light yield of GS20 is 6000 photons $/ \mathrm{MeV}^{(7)}$ the peaks generated by the monocrystalline $\mathrm{Li}_{2} \mathrm{~B}_{4} \mathrm{O}_{7}$ sample are equivalent to the peaks for 50 and 160 photons/neutron. It is assumed that the polycrystalline $\mathrm{Li}_{2} \mathrm{~B}_{4} \mathrm{O}_{7}$ sample has a lower light yield than the monocrystalline $\mathrm{Li}_{2} \mathrm{~B}_{4} \mathrm{O}_{7}$ sample because the pulse height spectrum of the polycrystalline $\mathrm{Li}_{2} \mathrm{~B}_{4} \mathrm{O}_{7}$ sample did not show any signals exceeding the thermal noise level of the PMT located at the channel lower than the two peaks generated by the monocrystalline sample. Only the monocrystalline $\mathrm{Li}_{2} \mathrm{~B}_{4} \mathrm{O}_{7}$ sample acted as the neutron scintillator.

Figure 6 shows TL glow curves of the monocrystalline and polycrystalline $\mathrm{Li}_{2} \mathrm{~B}_{4} \mathrm{O}_{7}$ samples after 3 Gy of X-ray irradiation. The monocrystalline $\mathrm{Li}_{2} \mathrm{~B}_{4} \mathrm{O}_{7}$ sample shows broad glow peaks at approximately 60,120 , and $150{ }^{\circ} \mathrm{C}$, and the polycrystalline $\mathrm{Li}_{2} \mathrm{~B}_{4} \mathrm{O}_{7}$ sample shows a high-intensity peak at approximately $120{ }^{\circ} \mathrm{C}$ and a broad peak at approximately $220{ }^{\circ} \mathrm{C}$. This difference in the glow curves is due to the difference in trapping center density between the samples. In general, the glow peak temperature depends on the energy depth of trapping centers. Because both samples show a continuous distribution in the glow curves, it is considered that both samples have various energy levels of trapping centers. Both samples show TL emissions in similar temperature ranges, but the intensity ratios of their glow peaks seem to be different. In the polycrystalline $\mathrm{Li}_{2} \mathrm{~B}_{4} \mathrm{O}_{7}$ sample, the peak intensity at $120{ }^{\circ} \mathrm{C}$ is higher than those at other temperatures. This is possibly due to an increase in the density of some trapping centers with similar energy depths equivalent to the glow peak at $120{ }^{\circ} \mathrm{C}$, but the details are unclear. In addition, although the monocrystalline $\mathrm{Li}_{2} \mathrm{~B}_{4} \mathrm{O}_{7}$ sample has an advantage in the light extraction efficiency from its inner parts owing to its highly transparent body, the TL intensity 


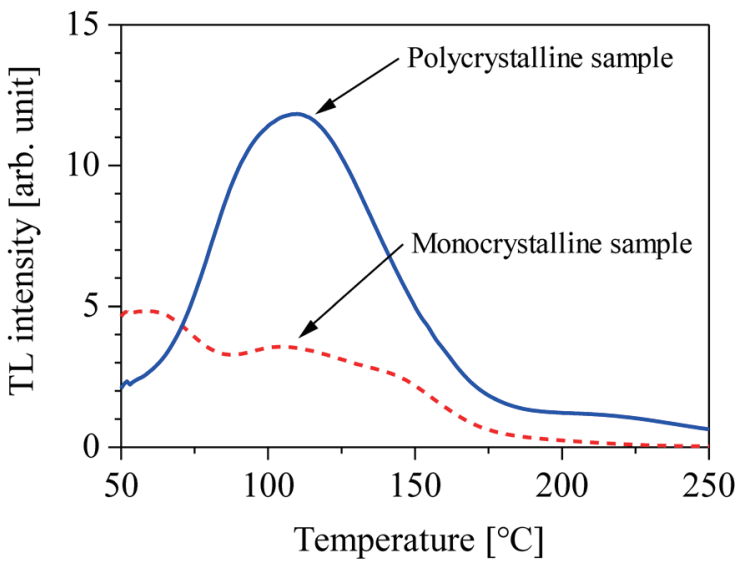

Fig. 6. (Color online) TL glow curves of monocrystalline and polycrystalline $\mathrm{Li}_{2} \mathrm{~B}_{4} \mathrm{O}_{7}$ samples after 3 Gy of X-ray irradiation.

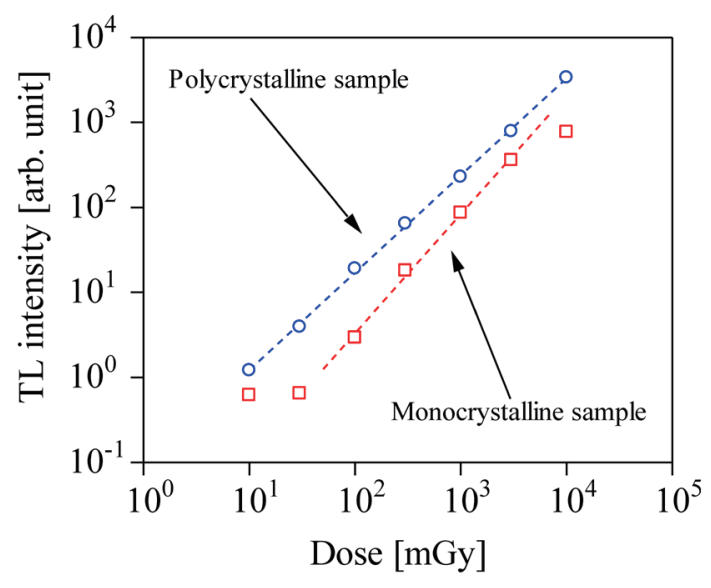

Fig. 7. (Color online) TL dose-response curves of monocrystalline and polycrystalline $\mathrm{Li}_{2} \mathrm{~B}_{4} \mathrm{O}_{7}$ samples.

of the polycrystalline $\mathrm{Li}_{2} \mathrm{~B}_{4} \mathrm{O}_{7}$ sample is higher than that of the monocrystalline $\mathrm{Li}_{2} \mathrm{~B}_{4} \mathrm{O}_{7}$ sample. Figure 7 shows TL dose-response curves of the monocrystalline and polycrystalline $\mathrm{Li}_{2} \mathrm{~B}_{4} \mathrm{O}_{7}$ samples. In the case of the $\mathrm{Li}_{2} \mathrm{~B}_{4} \mathrm{O}_{7}$ monocrystalline sample, a monotonic increase in its TL intensity is observed in the range of $100 \mathrm{mGy}$ to $3 \mathrm{~Gy}$. In contrast, in the case of the polycrystalline $\mathrm{Li}_{2} \mathrm{~B}_{4} \mathrm{O}_{7}$ sample, a monotonic increase in its TL intensity is observed in a wide range from $10 \mathrm{mGy}$ to $10 \mathrm{~Gy}$ owing to its high TL intensity. The polycrystalline $\mathrm{Li}_{2} \mathrm{~B}_{4} \mathrm{O}_{7}$ sample clearly shows better dosimetric properties than the $\mathrm{Li}_{2} \mathrm{~B}_{4} \mathrm{O}_{7}$ monocrystalline sample. The TL intensity of the monocrystalline $\mathrm{Li}_{2} \mathrm{~B}_{4} \mathrm{O}_{7}$ sample saturates at 10 Gy owing to its lower trap concentration.

In summary, the monocrystalline $\mathrm{Li}_{2} \mathrm{~B}_{4} \mathrm{O}_{7}$ sample showed a higher light yield than the polycrystalline sample and, conversely, the polycrystalline sample showed a higher $\mathrm{TL}$ intensity than the monocrystalline $\mathrm{Li}_{2} \mathrm{~B}_{4} \mathrm{O}_{7}$ sample. This result can be explained by the trap concentration of the polycrystalline $\mathrm{Li}_{2} \mathrm{~B}_{4} \mathrm{O}_{7}$ sample being higher than that of the monocrystalline $\mathrm{Li}_{2} \mathrm{~B}_{4} \mathrm{O}_{7}$ sample. In general, trapping centers are related to crystal defects and a lower defect concentration is expected in the monocrystalline $\mathrm{Li}_{2} \mathrm{~B}_{4} \mathrm{O}_{7}$ sample obtained by the well-established growth technique. In addition, the polycrystalline $\mathrm{Li}_{2} \mathrm{~B}_{4} \mathrm{O}_{7}$ sample can have a larger number of dangling bonds on the surfaces of its grains than the monocrystalline $\mathrm{Li}_{2} \mathrm{~B}_{4} \mathrm{O}_{7}$ samples without grains.

\section{Conclusions}

Scintillation and dosimetric properties of monocrystalline and polycrystalline $\mathrm{Li}_{2} \mathrm{~B}_{4} \mathrm{O}_{7}$ samples were studied. In the pulse height spectrum under neutron irradiation, the monocrystalline $\mathrm{Li}_{2} \mathrm{~B}_{4} \mathrm{O}_{7}$ sample showed two detection peaks owing to nuclear reactions of ${ }^{6} \mathrm{Li}$ and ${ }^{10} \mathrm{~B}$ with neutrons. It is concluded that the light yield of the monocrystalline $\mathrm{Li}_{2} \mathrm{~B}_{4} \mathrm{O}_{7}$ sample is higher than that of the polycrystalline $\mathrm{Li}_{2} \mathrm{~B}_{4} \mathrm{O}_{7}$ sample that showed no peaks 
exceeding the thermal noise level of the PMT. In contrast, the polycrystalline $\mathrm{Li}_{2} \mathrm{~B}_{4} \mathrm{O}_{7}$ sample showed a higher TL intensity than the monocrystalline $\mathrm{Li}_{2} \mathrm{~B}_{4} \mathrm{O}_{7}$ sample. The TL intensity of the polycrystalline $\mathrm{Li}_{2} \mathrm{~B}_{4} \mathrm{O}_{7}$ sample monotonically increased with the X-ray dose in a wider range from $10 \mathrm{mGy}$ to $10 \mathrm{~Gy}$ than that of the monocrystalline $\mathrm{Li}_{2} \mathrm{~B}_{4} \mathrm{O}_{7}$ sample. From these results, it is assumed that the monocrystalline $\mathrm{Li}_{2} \mathrm{~B}_{4} \mathrm{O}_{7}$ sample has a lower trap concentration than the polycrystalline $\mathrm{Li}_{2} \mathrm{~B}_{4} \mathrm{O}_{7}$ sample. This lower trap concentration can be achieved using a high-quality single crystal with a lower crystal defect density.

\section{Acknowledgments}

This work was supported by a Grant-in-Aid for Scientific Research A (17H01375) and for Early-Career Scientists (18K14158) from the Japan Society for the Promotion of Science (JSPS). The Cooperative Research Project of the Research Institute of Electronics, Shizuoka University, Iketani Science and Technology Foundation, NSG Foundation, and Murata Foundation are also acknowledged. The authors wish to thank Takahiro Kojima, a Research Engineer of OXIDE Corporation (https://www.opt-oxide.com/en/), for supplying the high-quality Li2B4O7 single crystal.

\section{References}

1 G. F. Knoll: Radiation Detection and Measurement (Wiley, New York, 2010) 4th ed.

2 C. W. E. van Eijk: Nucl. Instrum. Methods Phys. Res., Sect. A 460 (2001) 1.

3 T. Yanagida: Opt. Mater. 35 (2013) 1987.

4 C. W. E. van Eijk: Phys. Med. Biol. 47 (2002) R85.

5 S. E. Derenzo, M. J. Weber, E. Bourret-Courchesne, and M. K. Klintenberg: Nucl. Instrum. Methods Phys. Res., Sect. A 505 (2003) 111.

6 N. Kawaguchi, H. Kimura, M. Akatsuka, G. Okada, N. Kawano, K. Fukuda, and T. Yanagida: Sens. Mater. 30 (2018) 1585.

7 C. W. E. van Eijk: Nucl. Instrum. Methods Phys. Res., Sect. A 529 (2004) 260.

8 C. W. E. van Eijk: IEEE T. Nucl. Sci. 59 (2012) 2242.

9 N. Kawaguchi, T. Yanagida, Y. Fujimoto, Y. Yokota, K. Kamada, K. Fukuda, T. Suyama, K. Watanabe, A. Yamazaki, V. Chani, and A. Yoshikawa: Nucl. Instrum. Methods Phys. Res., Sect. A 652 (2011) 351.

10 N. Kawaguchi, K. Fukuda, T. Yanagida, Y. Fujimoto, Y. Yokota, T. Suyama, K. Watanabe, A. Yamazaki, and A. Yoshikawa: Nucl. Instrum. Methods Phys. Res., Sect. A 652 (2011) 209.

11 N. Kawaguchi, N. Kawano, G. Okada, and T. Yanagida: Sens. Mater. 29 (2017) 1431.

12 R.S. Holt, M.J. Cooper, and D.F. Jackson: Nucl. Instrum. Methods 221 (1984) 98.

13 C.L. Melcher: Nucl. Instrum. Methods Phys. Res., Sect. B 40/41 (1989) 1214.

14 N. Kawaguchi, G. Okada, K. Fukuda, and T. Yanagida: Nucl. Instrum. Methods Phys. Res., Sect. A (in press). https://doi.org/10.1016/j.nima.2018.10.196

15 T. Oya, D. Nakauchi, G. Okada, N. Kawaguchi, and T. Yanagida: Nucl. Instrum. Methods Phys. Res., Sect. A 866 (2017) 134.

16 D. Nakauchi, G. Okada, N. Kawano, N. Kawaguchi, and T. Yanagida: Appl. Phys. Express 10 (2017) 072601.

17 G. Okada, M. Akatsuka, H. Kimura, M. Mori, N. Kawano, N. Kawaguchi, and T. Yanagida: Sens. Mater. 30 (2018) 1547.

18 Y. Fujimoto, K. Saeki, D. Nakauchi, T. Yanagida, M. Koshimizu, and K. Asai: Sens. Mater. 30 (2018) 1577.

19 M. Akatsuka, Y. Usui, D. Nakauchi, G. Okada, N. Kawaguchi, and T. Yanagida: Sens. Mater. 30 (2018) 1525.

20 T. Yanagida, H. Masai, M. Koshimizu, and N. Kawaguchi: Sens. Mater. 31 (2019) 1225.

21 H. Kimura, T. Kato, D. Nakauchi, M. Koshimizu, N. Kawaguchi, and T. Yanagida: Sens. Mater. 31 (2019) 1265.

22 Y. Fujimoto, K. Saeki, D. Nakauchi, T. Yanagida, M. Koshimizu, and K. Asai: Sens. Mater. 31 (2019) 1241. 
23 D. Shiratori, Y. Isokawa, N. Kawaguchi, and T. Yanagida: Sens. Mater. 31 (2019) 1281

24 D. Nakauchi, N. Kawaguchi, and T. Yanagida: Sens. Mater. 31 (2019) 1249.

25 H. Fukushima, D. Nakauchi, N. Kawaguchi, and T. Yanagida: Sens. Mater. 31 (2019) 1273.

26 M. Akatsuka, D. Nakauchi, N. Kawaguchi, and T. Yanagida: Sens. Mater. 31 (2019) 1289.

27 N. Kawano, M. Koshimizu, G. Okada, Y. Fujimoto, N. Kawaguchi, T. Yanagida, and K. Asai: Sci. Rep. 7 (2017) 14754.

28 M. Koshimizu, T. Yanagida, R. Kamishima, Y. Fujimoto, and K. Asai: Sens. Mater. 31 (2019) 1233.

29 T. Yanagida, G. Okada and N. Kawaguchi: J. Lumin. 207 (2019) 14.

30 S. W. S. McKeever: Thermoluminescence of Solids (Cambridge University Press, Cambridge, 1985).

31 E. G. Yukihara and S. W. S. McKeever: Optically Stimulated Luminescence (Wiley, Chichester, UK, 2011).

32 S. W. S. McKeever: Nucl. Instrum. Methods Phys. Res., Sect. B 184 (2001) 29.

33 Y. Miyamoto, T. Yamamoto, K. Kinoshita, S. Koyama, Y. Takei, H. Nanto, Y. Shimotsuma, M. Sakakura, K. Miura, and K. Hirao: Radiat. Meas. 45 (2010) 546.

34 H. Nanto, Y. Miyamoto, T. Oono, Y. Takei, T. Kurobori, and T. Yamamoto: Procedia Eng. 25 (2011) 231.

35 Y. Miyamoto, H. Nanto, T. Kurobori, Y. Fujimoto, T. Yanagida, J. Ueda, S. Tanabe, and T. Yamamoto: Radiat. Meas. 71 (2014) 529.

36 Y. Koba, R. Shimomura, W. Chang, K. Shinsho, S. Yanagisawa, G. Wakabayashi, K. Matsumoto, H. Ushiba, and T. Ando: Sens. Mater. 30 (2018) 1599.

37 K. Shinsho, D. Maruyama, S. Yanagisawa, Y. Koba, M. Kakuta, K. Matsumoto, H. Ushiba, T. Andoh: Sens. Mater. 30 (2018) 1591.

38 N. Kawaguchi, D. Nakauchi, S. Hirano, N. Kawano, G. Okada, K. Fukuda, and T. Yanagida: Jpn. J. Appl. Phys. 57 (2018) 02CB13.

39 N. Kawaguchi, N. Kawano, G. Okada, and T. Yanagida: J. Lumin. 206 (2019) 634.

40 T. D. Gustafson, E. D. Milliken, L. G. Jacobsohn, and E. G. Yukihara: J. Lumin. 212 (2019) 242.

41 V. B. Pawade, M. M. Kolte, N. R. Kakade, and S. J. Dhoble: Optik 203 (2020) 164004.

42 A. Ozdemir, N. Can, K. Kurt, and Z. Yegingil: J. Alloys Compd. 751 (2018) 159.

43 G. Okada, T. Kojima, J. Ushizawa, N. Kawaguchi, T. Yanagida: Curr. Appl. Phys. 17 (2017) 422.

44 F. Nakamura, T. Kato, G. Okada, N. Kawaguchi, K. Fukuda, and T. Yanagida: Ceram. Int. 43 (2017) 7211.

45 F. Nakamura, T. Kato, G. Okada, N. Kawaguchi, K. Fukuda, and T. Yanagida: J. Eur. Ceram. Soc. 37 (2017) 1707.

46 N. Kawaguchi and T. Yanagida: Sens. Mater. 31 (2019) 1257.

47 N. Kawaguchi, H. Masai, H. Kimura, G. Okada, and T. Yanagida: J. Non-Cryst. Solids 501 (2018) 126.

48 H. Kimura, F. Nakamura, T. Kato, D. Nakauchi, G. Okada, N. Kawaguchi, and T. Yanagida: Sens. Mater. 30 (2018) 1555.

49 T. Yanagida, Y. Fujimoto, K. Watanabe, K. Fukuda, N. Kawaguchi, Y. Miyamoto, and H. Nanto: Radiat. Meas. 71 (2014) 162.

50 M. Kobayashi, M. Ishii, and N. Senguttuvan: Problemy Spektroskopii i Spektrometrii 34 (2015) 71. arXiv:1503.03759

51 L. Singh, V. Chopra, and S. P. Lochab: J. Lumin. 131 (2011) 1177.

52 C. Guarneros-Aguilar, E. Cruz-Zaragoza, J. Marcazzó, R. Palomino-Merino, and J. E. Espinosa: AIP Conf. Proc. 1544 (2013) 70.

53 V. E. Kafadar, R. G. Yildirim, H. Zebari, and D. Zebari: Thermochim. Acta 575 (2014) 300.

54 T. Yanagida, K. Kamada, Y. Fujimoto, H. Yagi, and T. Yanagitani: Opt. Mater. 35 (2013) 2480.

55 T. Sugawara, R. Komatsu, and S. Uda: Solid State Commun. 107 (1998) 233. 